Recognising and responding to young people with learning disabilities who experience, or are at risk of, child sexual exploitation in the UK.

Anita Franklin ${ }^{1}$, Coventry University, UK and Emilie Smeaton ${ }^{2}$, Paradigm Research, UK.

\footnotetext{
${ }^{1}$ Coventry University, Priory Street, Coventry, UK. Email: anita.franklin@coventry.ac.uk

${ }^{2}$ Paradigm Research. Email: emilie.smeaton@paradigm.co.uk
}

Corresponding author: Anita Franklin - anita.franklin@coventry.ac.uk 


\section{Recognising and responding to young people with learning disabilities who experience, or are at risk of, child sexual exploitation in the UK.}

\section{Introduction}

Child sexual exploitation (CSE) is a form of child sexual abuse (CSA) involving children under the age of 18. Specific to CSE is the concept of exchange where children who are abused or the person, or persons, abusing them receive something in return for the abusive act. The abuse may be exchanged for drugs or alcohol, for example, or for affection. The element of exchange does not mean that the sex is consensual or that it is not abusive, in fact it can compound the abuse as children's needs are exploited and the exchange can be used to groom and control children. CSE can be perpetrated by male and female adults and children's peers and can affect children of any age, in both urban and rural settings and from all social backgrounds irrespective of gender and ethnicity. English guidance to safeguard children and young people from CSE states that:

'Child sexual exploitation can occur through use of technology without the child's immediate recognition, for example the persuasion to post sexual images on the internet/mobile phones with no immediate payment or gain. In all cases those exploiting the child/young person have power over them by virtue of their age, gender, intellect, physical strength and/or economic or other resources. Violence, coercion and intimidation are common, involvement in exploitative relationships being characterised in the main by the child or young person's limited availability of choice resulting from their social/economic or other resources.' (Department for Children, Schools and Families, 2009, p9).

\subsection{Policy context}

All four UK nations have developed specific guidance and/or action plans to safeguard children from sexual exploitation. Currently, the English government is updating its 2009 guidance to reflect the growing evidence base on CSE and in light of a number of high profile enquires into failures by local authorities to protect children from sexual exploitation (See for example, Bedford, 2015; Jay, 2014; Coffey, 2014; Rochdale Borough Safeguarding Children Board, 2012). In Northern Ireland (NI), the issue of CSE was brought to the fore in 2011 (Beckett, 2011) and led to a subsequent independent enquiry and commitment to develop a coordinated and consistent multi-agency approach to tackle CSE (Marshall, 2014). While learning disability is not specifically mentioned in the NI strategic plan, disabled children are noted as a priority group requiring protection from abuse (Safeguarding Board 
for Northern Ireland, 2013). Similarly in Scotland, the Scottish government instigated an inquiry into CSE in 2013. The inquiry report notes the:

'definite gap in knowledge about disabled children and young people in relation to child sexual exploitation' (Scottish Parliament, 2014, p28).

Following this, the Scottish Government published a refresh of the National Guidance for Child Protection in Scotland with a separate section on CSE (Scottish Government, 2014). These guidelines contain a specific section on disabled children and have been further supplemented by the Child Protection and Disability Toolkit (WithScotland, 2014). In 2014, the Scottish Government published Scotland's National Action Plan to Tackle Child Sexual Exploitation, however, this contains no reference to children with learning disabilities. Similarly, in 2011, the Welsh Assembly Government published their guidance on safeguarding children from sexual exploitation. This document identifies that children with 'special needs' are particularly vulnerable to sexual exploitation and makes specific reference to young people aged 18 and over with learning disabilities:

'When a young person has a learning disability and is entitled to receive support via adult services, transition arrangements should take account of any risk to, history of or current abuse through CSE. Children's services should ensure that they draw any specific needs in relation to the young person's on-going safety and protection to the attention of colleagues in adults' services to enable on-going care plans to reflect these specific needs.' (Welsh Assembly Government, 2011, p 38).

All of these UK government documents recognise that although any child may be at risk of sexual exploitation, disabled children may be particularly vulnerable, and/or that sexual exploitation can be related to other factors in the life of a child, including learning disabilities. Some of the guidance also note how perpetrators can target disabled children and that strategies, procedures and provision will need to be adapted to meet their particular needs (DCSF, 2009: $p$ 39). This has led to the proliferation of risk assessment tools which include learning disability as a vulnerability factor (see for example: Health and Social Care in Northern Ireland, 2014; Sexual Exploitation and Risk Assessment Form (SERAF), Welsh Assembly Government, 2011; NWG Network Child Sexual Exploitation (CSE) Risk Assessment Tool (date unknown). Although the evidence on which these risk assessment tools have been based has been the subject of scrutiny (Brown et al, 2016).

However, much of this is guidance for local authorities and therefore does not have a legal status. In light of this lack of statutory duty, implementation has been shown to be patchy. The way in which the English government 2009 statutory guidance has been implemented was the subject of a two-year research study which identified that only a quarter of local 
authorities had implemented any of the suggested guidance (Jago et al, 2011). Berelowitz et al, have also highlighted the deficiencies in implementing the guidance to protect children in gang-related child sexual exploitation (2015).

\subsection{Prevalence of CSE of disabled children}

Although CSE can be by its very nature difficult to detect, a growing body of evidence has given some indication of the extent of CSE, the different forms it takes and its impact on victims in the UK. This literature highlights that often children with learning disabilities constitute a significant minority of sexually exploited children (Fox, 2016; Brodie and Pearce, 2012; Smeaton, 2009) and that children with learning disabilities or difficulties are at increased risk of CSE (Beckett, 2011; Smeaton, 2013; Berelowitz, 2013).

Identification of CSE is exacerbated by children not necessarily being aware that they are being exploited and therefore not seeking support. Of course, the onus should not be on children to recognise their own abuse, all adults have a responsibility to protect children. However, the research evidence points to professionals' lack of awareness and knowledge of the indicators of CSE leading to the under recognition and recording of sexual exploitation at a local level. Different local assessment processes can also exacerbate the difficulties in estimating the extent of CSE on a national level. As noted by the Child Exploitation and Online Protection Centre (CEOP), the lack of a single system to record and monitor CSE significantly undermines the possibility of building a national picture of the extent of CSE across the UK (2011). Identifying within this the prevalence of children with learning disabilities is a further challenge. Processes do not necessarily record a disability and many children would not necessarily have a formal diagnosis, have undergone a formal assessment of their learning needs or met the high threshold for services; so information on learning disability might not be known or not recorded consistently or accurately.

The invisibility of disabled children within prevalence studies of abuse generally is common. In addition, disabled children are often treated as one homogenous group, making it difficult to establish accurately the prevalence of the abuse of children with learning disabilities or communication needs, for example. However, research has found that disabled children are more likely to be abused than their non-disabled peers. A meta-analysis of 17 studies of violence against disabled children (representing over 18,000 individuals) illustrates that this group is between three and four times more likely to experience violence than non-disabled children (Jones et al, 2012). For sexual violence, estimates of prevalence are 8-9 per cent; however, when examining the prevalence of sexual violence in children with mental or intellectual disabilities specifically, the figure rises to 15 per cent. Studies have also 
indicated that disabled children are less likely to disclose abuse and more likely to delay disclosure than their non-disabled peers (Hershkowitz et al, 2007).

\subsection{Abuse of disabled children}

In general, the quality and quantity of information on the abuse and protection of disabled children in the UK is poor. Evidence suggests that the increased vulnerability of disabled children is linked to:

- the lack of priority given to this group within local strategic arrangements to protect children (National Working Group on Safeguarding Disabled Children, 2016)

- the lack of attention given in practice guidance and supervision of workers to the increased vulnerability of disabled children to abuse (Taylor et al, 2014)

- the reactions of professionals to the child, if they disclose, including disbelief and a failure of professionals to seek the views of disabled children (Miller and Brown, 2014; Taylor et al, 2014)

- lack of confidence amongst child protection practitioners working with disabled children, especially when the child has a communication impairment (Stalker et al, 2010; Taylor et al, 2014)

- professionals being too parent-focused and losing sight of the child (Taylor et al, 2014)

- variations in the thresholds that trigger a child protection response where disabled children are involved (Ofsted, 2012)

- services and support not understanding different types of impairment and associated support needs and in turn how this might affect a disabled child's risk of abuse and possible interventions (Taylor at el, 2014)

- a lack of sex and relationships education and awareness of abuse amongst disabled children and little attention placed on preventative work with this group (Taylor at al, 2014; Taylor et al, 2015; Jones et al, 2016)

- disempowerment of disabled children and disabling attitudes which encourage passivity and dependence and creates vulnerability and impacts on a child's confidence to disclose (National Working Group on Child Protection and Disability, 2003; Davies, 2013; Miller and Brown, 2014; Taylor et al, 2014; Taylor et al, 2015; Jones et al, 2016).

Research focused on CSE in relation to children with learning disabilities has thus far been very limited. This research sought to address this gap and further our understanding of how to recognise and respond to children with learning disabilities who have experienced, or who 
are at risk of, sexual exploitation. The term young people will subsequently be used to reflect the older age range of those involved in the study, although it is acknowledged that anyone under the age of 18 years is recognised as a child in UK law.

Whilst it is recognised that several definitions of learning disability are used in the UK and internationally, this research was guided by the following which states that a learning disability meets three criteria:

- a significantly reduced ability to understand new or complex information, to learn new skills (impaired intelligence) with:

- $\quad$ a reduced ability to cope independently (impaired functioning);

- which started before childhood, with a lasting effect on development. (Department of Health, 2001).

This definition was used to identify the sample of children for the study. However, the research was guided by the social model of disability, which locates disability in the social, cultural, material and attitudinal barriers that exclude people with impairments from mainstream life, as opposed to looking at the individual in terms of 'deficit'. This approach underpinned the methodological design, ensuring that any personal or social barriers children with learning disabilities might face to participating in the study were identified and addressed. Operating within the social model of disability meant that selection and recruitment of the sample was guided by practitioners who identified children who faced barriers to learning.

\section{Aims of the study}

Specifically, the research undertook to:

1) detail current provision of services for disabled children

2) explore the views of practitioners, managers and local and national policymakers looking into both enablers of and barriers to good practice

3) understand the needs of children and young people with learning disabilities who are at risk of, or who have experienced, CSE, and gather their views on current practice

4) identify gaps in policy, provision, evidence and research

5) generate evidence-based recommendations for future developments in this area of work. These aims were defined by the funder.

This paper presents an overview of some of the key findings. For the full report please see XXXX. 


\section{Methodology and sample}

The study encompassed both qualitative and quantitative data collection across the UK. The research consisted of multiple stages.

a) An on-line survey of all local authorities across the UK

Local authorities in England, NI, Scotland and Wales were emailed a link to a secure online survey and invited to participate. The aim of the survey was to gather a comprehensive picture of practice and policy at a strategic and operational level, and explore implementation of guidance. The survey was administered electronically and was fully compliant with UK data protection laws. An overall response rate of 34 per cent was achieved.

b) On-line surveys of services supporting either vulnerable or disabled children and young people

Due to a lack of a comprehensive database of CSE or disability services across the UK a convenience sample had to be utilised. Surveys were distributed widely through networks, known contacts and a snowballing approach; thus the exact number who received the survey is unknown. The surveys did not aim to be representative, but explored relevant issues with specialists and practitioners in the field. Overall twenty-three services responded to a survey targeted at specialist practice with vulnerable young people. Fourteen responses were received from specialist CSE services and nine from services that worked more broadly with disadvantaged young people. Three respondents had a specific focus on working with young people with learning disabilities and CSE. These services worked with young people with an age range of eight to 25 years, and were mostly from the voluntary sector. Fourteen services responded to the survey targeted towards those working with young people with learning disabilities. These services supported young people aged from the age of 0 to 25 years.

c) In-depth semi-structured telephone or face-to-face interviews with statutory and voluntary sector stakeholders

In order to explore in more depth barriers and enablers to good practice and policy implications, interviews were conducted with 34 key stakeholders working in the field of CSE and/or learning disability across the UK. These professionals represented both frontline and strategic-level roles: 11 were recruited from the statutory sector, with representation across social care, police, health and education, and 23 from the voluntary sector. Most of the interviews were carried out on an individual basis and via telephone.

The interviews explored: current provision; multi-agency working; gaps in local and national practice and policy provision; barriers to and facilitators of identifying and supporting this 
group of young people; skills and training needs; and approaches to recording and monitoring. Professionals who delivered direct services were asked to explain how they supported young people with learning disabilities who experience, or are at risk of, CSE, what facilitated and hindered their work and how they would like to improve and develop future practice.

d) Face-to-face interviews with young people with learning disabilities who have experienced, or been at risk of, CSE

The interview schedule, information sheets and consent forms for recruitment of young people were developed and piloted in consultation with an advisory group of five young people with learning disabilities who were recruited from, and being supported, by two CSE specialist services. An interview schedule organised around themes was developed and was designed flexibly to ensure that all the young people were given the best possible opportunity to discuss their experiences and express their feelings about them.

Young people with learning disabilities who had experienced CSE, or been identified as being at risk of CSE while under the age of 18, were invited to take part in face-to-face interviews. Young people were recruited from specialist CSE services and services providing support to young people with learning disabilities from across the UK. These services utilised different assessments tools to determine risk of CSE, and thus the sample of young people within the study deemed at risk was determined by whether they met the variable thresholds for CSE services.

Support workers were asked whether recruitment materials needed to be adapted to meet any individual access need, but this was not deemed necessary for any of the individuals they approached. Selection and recruitment of the sample was guided by specialist services who identified young people with learning needs and who were in a position where it was deemed that they would be able to cope with taking part in the research. This approach ensured the inclusion of young people who had experienced, or been at risk of, CSE and who had a formal diagnosis of learning disability, as well as those with a learning need who had not been formally assessed, or who may not have received any additional support to help them in their learning. This proved to be important and has shed light on the potentially high numbers of children and young with moderate/mild learning disabilities who are at risk of, or have experienced, CSE and how this group of young people are not being adequately identified and supported.

All interviews were undertaken by two researchers with experience in child protection and disabled children. The young people were not asked directly about their experiences of CSE but rather about their experiences of support from professionals, any difference this support 
had made to their life and their views about what should be done to meet the needs of young people with learning disabilities. Previous studies in the maltreatment of disabled children and vulnerable groups show the importance of obtaining contextual information to supplement the data collected from young people (Taylor et al, 2015, Franklin and Doyle, 2013). With a young person's consent, their support worker from the specialist service was contacted in advance of the young person's interview to gather supplementary contextual information about their individual circumstances. Information on accessibility needs was also collected, including any communication needs, to enable the researcher to prepare an accessible interview. All interviews were conducted verbally and adapted to each young person to ensure that the length, format and approach enabled their full participation. With the young person's permission, interviews were digitally recorded. In three cases individuals did not want to be recorded and notes were taken. Given the sensitive nature of this topic area, specific attention was given to ensuring an ethical and supportive approach was undertaken in preparation for, during and after the interviews. Care was taken to ensure that the young people gave informed consent throughout the interview and understood the limitations of anonymity and confidentiality in the event of safeguarding concerns. Parental/guardian permission was also sought for those aged under 16 years. This is explained further in XXX. At the end of the interview, young people were reminded that they could withdraw permission for the data from their interview to be included in the study for a period of four weeks after the interview. This gave the young people an opportunity to reflect on what they had said. None chose to do this and it should be noted that although they were not asked about their experiences of exploitation, many young people chose to relay their personal story. Twenty-seven young people with learning disabilities were interviewed.

Table 1: Sample of young people interviewed $(n=27)$

\begin{tabular}{|l|l|}
\hline Age range & $\begin{array}{l}12 \text { to } 23 \text { years (19 were still under 18 years at } \\
\text { the time of the interview) }\end{array}$ \\
\hline Gender & 7 male and 20 female \\
\hline Ethnicity & $\begin{array}{l}22 \text { White British, 3 White/Asian, 2 Black } \\
\text { Caribbean. }\end{array}$ \\
\hline Experienced CSE/At risk of CSE & $\begin{array}{l}15 \text { identified as having experienced CSE, } 12 \\
\text { deemed at risk of CSE }\end{array}$ \\
\hline Additional identified impairments & $\begin{array}{l}\text { Autistic Spectrum Conditions (ACS) including } \\
\text { Asperger syndrome (6), long-term medical or } \\
\text { health conditions (5), Attention Deficit } \\
\text { Hyperactivity Disorder (ADHD) (3), dyspraxia } \\
(2), \text { mental health needs (2) and one recording }\end{array}$ \\
\hline
\end{tabular}




\begin{tabular}{|c|c|}
\hline & $\begin{array}{l}\text { of attachment disorders, emotional deregulation } \\
\text { disorder and dyslexia** }\end{array}$ \\
\hline Living arrangements & $\begin{array}{l}17 \text { lived with their family, } 4 \text { were currently in } \\
\text { care, } 1 \text { lived in a hostel, } 1 \text { in supported } \\
\text { accommodation, } 1 \text { was staying with friends and } \\
2 \text { were living with partners. Information on the } \\
\text { living arrangements of one young person was } \\
\text { not given. }\end{array}$ \\
\hline Educational provision/employment & $\begin{array}{l}8 \text { were in school (four in mainstream and four in } \\
\text { special schools), } 8 \text { were in college (one of } \\
\text { whom attended a specialist college), } 3 \text { attended } \\
\text { a form of alternative education provision, } 5 \text { were } \\
\text { not in education, employment or training } \\
\text { (NEET), } 1 \text { was working part-time, and this } \\
\text { information was not available on two young } \\
\text { people. }\end{array}$ \\
\hline
\end{tabular}

*It should be noted that CSE specialist workers reported that it is quite often the case that they support young people considered at risk of CSE and at a later date a disclosure or discovery of sexual exploitation occurs, so it is possible that more of the sample of the young people could be experiencing CSE, or had experienced CSE at the time of interview than identified.

** None of the young people were described as having specific or significant communication needs, and all communicated verbally in their interviews.

\section{Ethics and governance}

Ethical approval was granted by XXXX University's Ethics Committee and by [partner agency] Research Ethics Committee. An IRAS (Integrated Research Application System) application had to be made in order to undertake the research in Northern Ireland. The storage and use of data complied with all data protection law in the UK and was stored in password-protected and encrypted files.

\section{Data analysis}

All survey data were descriptively analysed using SPSS software. Transcripts or detailed notes from the interviews were independently coded by two researchers using an 'inductive coding' approach. (Ritchie and Spencer, 1994). During the process the researchers deliberated and refined the codes, resulting in adjustments to coding. Discrepancies were discussed and resolved. Data were triangulated across the collection methods. Given the sensitive nature of this research, particular care was taken to ensuring the anonymity of the 
young people who participated in the study. All identifying details have been removed and all participants have been given a pseudonym.

\section{Findings:}

These findings present the main themes identified across all data collection methods. There was considerable consistency in the issues identified by all participants and in the potential solutions.

\subsection{Young people with learning disabilities are at particular risk of child sexual exploitation}

Supporting previous evidence on the abuse of disabled children, the findings from this study indicate that young people with learning disabilities are particularly vulnerable to sexual exploitation due to a number of factors that include: over protection, disempowerment, social isolation, a collective failure to teach this group of children and young people adequate sex and relationship education or to recognise their emerging sexuality as they get older. In addition, a failure of adults to notice the exploitation.

\subsection{Over protection}

The majority of professionals, and many of the young people, interviewed spoke at length about how young people with learning disabilities can be overprotected and not given opportunities to learn, develop and take risks in the same way as their non-disabled peers thus rendering them in effect unprotected. Examples of this included how young people's experiences of the world can be confined to a door-to-door taxi or bus service to and from a special school. In addition a few of the young people interviewed explained that they had not been adequately prepared for adulthood and as soon as they had gained some independence they have been exploited, as Ellie's experiences reveal:

Ellie is now 23. She has a learning disability and describes herself as naïve and impulsive. Ellie is now in a loving, happy relationship, but experienced CSE shortly after moving into supported living accommodation when she turned 18.

Ellie described how, because of a medical condition, her special school insisted that her mum had to pick her up and drop her off every day and that she must not step outside the gate even if she could see her mum coming down the street. Ellie had little opportunity for socialising and was not prepared for adult life and for moving into supported living accommodation. She thought the man she met at her new home was her boyfriend, but he 
was controlling and isolated her from her family and then exploited her.

In line with Ellie's experience, a significant number of professionals also identified a lack of preparation for adulthood and independent living as an issue:

'It's not that we want to chuck young people with learning disabilities out into the real world when they're 18, but there's something about when they're 14, 15, 16, 17... we need to be preparing them for it and say: "This is the real world: sometimes it's not nice".'

The manner in which professionals and other adults treat young people with learning disabilities was seen by some professional interviewees to be infantilising or 'overly nice', thus leading to increased vulnerability:

'Lots of people are just so nice to young people, and adults, with learning disabilities and so patronising sometimes [...] and I'm wondering if, from a young age, these young people with learning disabilities are surrounded by people being nice to them and think that everybody is like that... and then when somebody tries telling them that not everybody is actually like that, they don't understand it because it's not what they know and it's outside of their understanding.'

\subsubsection{Disempowerment}

Professionals across the sample identified that the tendency for young people with learning disabilities not to be listened to, empowered or involved in decision-making about their lives could play a part in creating increased vulnerability to abuse and possibly influencing professionals' responses to some discloses of CSE. A lack of empowerment might also mean that disabled children might not think they will be listened to or believed and so remain silent.

\subsubsection{Social isolation of young people with learning disabilities}

The social isolation experienced by some young people with learning disabilities and a desire to cultivate friendships was identified during interviews as making them potentially more vulnerable to grooming and CSE. As one professional stated;

'Young people with learning disabilities are a perpetrator's dream...They're often lonely and isolated. Many of them have not had a boyfriend or a girlfriend but would 
like one. Many spend a lot of time online. They are less likely to understand that sexual exploitation is wrong and are so easy to groom.'

The desire to be seen as 'normal' was also viewed as a contributory factor in vulnerability to CSE. A practitioner described;

"Wanting to be "normal" is part of their teenage process and so they get caught on the edge of gangs, they get used by gangs, because they are vulnerable, they get sexually exploited within the gang and they also end up being the ones getting caught [when involved in criminal activity].'

A couple of the young people interviewed confirmed that they had turned to social networking to alleviate their social isolation and thus could become particularly vulnerable to being groomed online especially as they stated that at the time they had not understood how to keep safe online.

Professionals pointed out the benefits that the internet had brought to the lives of disabled people as well as the risks. However, it was widely reported across the samples that young people with learning disabilities might not have received good internet safety training, which is crucial.

\subsubsection{Lack of sex and relationships education and knowledge concerning sexual exploitation}

Across all data collection methods and samples, respondents repeatedly raised concerns about the lack of accessible sex and relationship education. Learning about how to keep safe especially online and when using social media, and understanding what exploitation is, was seen as vitally important but a missing element of most of these young people's lives. This was viewed as reflective of a general perception of disabled people as "asexual" (Shakespeare et al, 1996) and in the case of disabled young people a view that does not see them as displaying 'typical' teenager behaviour in terms of exploring relationships and sex. It was also reported to be linked to disbelief that young people with learning disabilities might become victims of sexual abuse and exploitation. As one professional described:

'We don't want to think that disabled young people have sex; we don't want to think that disabled young people can be exploited and be exploitative.'

A few young people interviewed said that they had not known that it was illegal for an adult to have sex with a child. They explained that it had been their CSE project worker or, in one case, a drop-in worker, who was the first person to explain this to them. Others reported that they did not know about grooming or what exploitation meant. Professionals identified an 
urgent need for education providers - both mainstream and in special schools and colleges - to become more involved in the CSE agenda.

'We need good sex education and awareness work with young people with learning disabilities, especially around boundaries, what is and isn't socially acceptable, how best to work with and empower these young people, and self-protection skills and undertaking safe risks.'

The small minority of young people who stated that they had received sex education reported that this had not adequately covered relationship issues, information concerning the giving and receiving of consent and how relationships can potentially be exploitative. Some of the young males who participated in the research had questions relating to their sexual orientation and did not know where to go to find information - seeking information online had placed them in vulnerable positions. It was also suggested by a small minority of professionals that this lack of education for young people with learning disabilities could partly be because they are not always present for sex and relationships education classes, as this time is often used for catching up on other lessons, potentially highlighting the lack of importance being placed on this education. In addition, it was thought that teachers and education providers in specialist and mainstream schools do not have relevant materials or expertise to teach sex and relationships education with young people with learning disabilities. It was noted by practitioners during interviews that good-quality sex and relationships education can only be delivered by paying full attention to understanding choice and consent, with recognition that the ability to assert and choose can be very challenging for some young people with learning disabilities. Interviewees repeatedly spoke of the need for time and dedicated support to explore these issues with young people.

Questions were included in the local authority survey to find out whether there was targeted awareness-raising concerning CSE being undertaken with parents/carers of young people with learning disabilities. Just over a third of respondents (34 per cent) said work was taking place in their area with parents/carers to help them identify CSE. However, examples of activities undertaken indicated that this work was only undertaken with families where a risk had already been identified, rather than with all families with a child with a learning disability as part of any preventative strategies.

Professionals from all of the UK nations, local authorities and across all sectors identified gaps in preventative work in general relating to CSE, and specifically with young people with learning disabilities. All of the young people interviewed stated that they had not learnt about 
CSE at their mainstream or special school or heard of CSE before being referred to a specialist CSE service.

\subsubsection{Failure of adults to recognise CSE}

Despite professional interviewees reporting some examples of good levels of knowledge, understanding and awareness of the sexual exploitation of young people with learning disabilities, the findings suggest that there is a general lack of awareness and little knowledge of how to both recognise CSE and how best to meet the needs of young people with learning disabilities who experience, or are at risk of, CSE. Many professionals reported that child protection professionals across the UK remain ill-informed about learning disability. Conversely interviewees suggested that there is a lack of knowledge, awareness and understanding of CSE among social workers within children's disability teams. This can lead to a lack of joint working between child protection professionals and those with a specialism in disability and silos in knowledge and understanding, leaving children with learning disabilities falling through a gap.

A number of professionals who were interviewed described how a lack of knowledge and understanding of CSE and impairments such as ASC and ADHD, in addition to a learning disability, can lead some professionals to view some young people with these impairments as 'challenging' and as a 'management problem', rather than recognising that their behaviour might mask their vulnerability, or is an outward sign that sexual exploitation is occurring. This perception was reported to be diverting attention from supporting their CSE needs. As one professional highlighted:

'We also had a young man referred [to the specialist CSE service] due to concerns around missing from home, getting involved in crime, starting to shoplift, starting to use drugs and alcohol and starting to become aggressive at home with family [...] and then you identify that, actually, there's all sorts of issues around autism, which they think is getting worse, and he's under review for other disabilities [but] those things are almost an aside: "Oh well, that's why he behaves the way he behaves" kind of thing, and the sexual exploitation being almost an: "Oh, right, so there's sexual exploitation too?".'

Not surprisingly, analysis of the research data indicated that to fully meet young people's needs, professionals need to be knowledgeable about both CSE and learning disabilities.

\subsection{Invisibility of young people with learning disabilities to services}


In interviews, many professionals reflected on a widely held view that large numbers of young people with learning disabilities are not being referred to receive support for CSE. Interviewees highlighted the issues:

'You're relying on people: one, understanding sexual exploitation; and two, actually being involved and being ready to recognise it and willing to report it. So there's a double assumption there that makes these young people even more vulnerable.'

It was also suggested that young people with mild/moderate learning disabilities may not meet the criteria for targeted services or have had any assessment of their learning needs, which can increase their risk of CSE as they are not necessarily on anyone's radar. Most professionals from specialist CSE services explained how work with a young person often raises concerns that the individual may have a learning disability that has not previously been assessed:

I have worked with young people where we have felt very strongly as a professional network that this young person has either a very severe learning difficulty or a learning disability [...] and they don't get a diagnosis - but yet, we're seeing young people where they've forgotten their name, or they can't do very simple self-care, and they can't travel independently.'

Specialist CSE workers reported that they find it is easier to meet the needs of a young person when there is a formal diagnosis of a learning disability as this enables them to access multi-agency support. They also identified that where there is no formal diagnosis being able to gain one can often have the beneficial consequences of getting the young person appropriate and/or specialist services to meet their learning needs. Throughout the data gathering it was evident that many young people had not had an assessment of their learning needs and/or did not meet the high threshold for disability support. One young person described how she had not been diagnosed with Asperger's syndrome until she was 13 years old, and that her needs had not been recognised:

I had to go to loads of different schools because I was just getting kicked out [of school] all the time... I wasn't going to lessons; just wasn't listening really. I was in trouble [at school] all the time: swearing at teachers... getting into fights...And because [school staff] didn't understand [that I had Asperger syndrome], I just got called a naughty child.' 
A significant number of the young people who were interviewed relayed a history of being outside of education and/or having a difficult time at school because they felt unsupported.

Professionals also raised concerns that often child care plans and assessments do not recognise the vulnerabilities of young people with learning disabilities and risk of CSE, possibly because of a lack of knowledge and awareness of CSE, as highlighted previously, and because of assessments being too educationally focused. They also raised concerns that assessments undertaken at a younger age should put in place preventative measures to avert risk:

If young people aren't being assessed [in relation to having a learning disability] when they're younger and before they come to [the CSE project], we're missing a massive opportunity to provide them with support and potentially putting them at risk.'

\subsection{Gaps in national and local policy and a lack of implementation of existing guidance}

Professional interviewees and survey responses highlighted key gaps in national policy and guidance, in particular the need for a clearer obligation on local authorities and services to implement guidance and provide services to meet the needs of this group of young people. Implementation of national policy and guidance was reported to be patchy across local authorities, although a small minority reported that they have started to implement some activities. For example, 41 per cent of local authorities stated in the survey that they have a specialist CSE service, but only half of these felt that the services were currently able to meet the needs of young people with learning disabilities. But worryingly, twenty-five per cent of local authorities without any specialist service said they do not have any other support available in its place.

Gaps in local authority provision were reported in the survey responses to include the lack of a clear and detailed focus on learning disability with limited attention on disability in multiagency CSE strategies which had been developed or were being developed. A very small minority of local authorities were reported to have a CSE "champion" for young people with learning disabilities whose role is to ensure that young people with learning disabilities are considered at strategic and operational level decision-making around CSE, this was seen as a positive way forward and a way to develop and ensure multi-agency focus. The importance of multi-agency working was highlighted by almost all professionals as being crucial to adequately responding to the complexity of CSE. As one professional stated:

'I think it is important to adopt a multi-agency approach in working with all young people and very important for schools and those caring for them to be trained in CSE 
to be able to 'spot the signs', raise concerns and work with agencies to help them communicate and support young people. Also improved access to and communication with health professionals and those responsible for assessing and diagnosing learning disabilities would help as it can be difficult to determine how to help and support a young person.'

\section{Discussion:}

This study has generated important data in an area that has received little attention to date. A particular strength of the research was being able to ensure that the voices of some young people with learning disabilities who had experienced, or were at risk of, CSE were heard, albeit just those receiving support. However, the limitations of the study must be acknowledged, whilst the study provides an exploratory overview of the current situation in the UK, much more detailed studies are now required to help to fully understand how we can both prevent CSE and respond to those who have experienced CSE - not least prevalence studies which would help to determine whether this is happening on an alarming scale as is the widespread belief reported by professionals working with this group of young people.

The increased vulnerability of disabled children to abuse is well known (Jones et al, 2012), but so far the extensive debate and focus concerning CSE in the UK has neglected, to a wide extent, this increased risk. Of course, young people with learning disabilities share many of the same vulnerabilities to CSE that are faced by all young people, but concerns have been raised through this study which illustrates that this group of young people face additional barriers to their protection, and to receiving support if they are at risk of, or have experienced, CSE. The reasons for this are multi-layered and complex and often appear to be entrenched in the way society perceives and treats young people with learning disabilities. Previous studies on disabled children's abuse point to the part that disablism can play in their lack of protection (Taylor et al, 2014; Miller and Brown, 2014; Taylor et al, 2015; Jones et al, 2016).

Part of tackling disablism and the lack of understanding is to raise awareness of the sexual exploitation of young people with learning disabilities, this research found that little work was being undertaken with families and their children, and with the wider professionals who might come into contact with young people with learning disabilities. The research identified that there remain significant gaps in professionals' knowledge of both CSE and learning disabilities and of how best to meet these children's needs. The need for multi-agency training at a local level for all professionals whose work includes responsibility for the safety and wellbeing of young people and their families is highlighted in the research as a priority. There is also a need for training focusing on learning disabilities, ASC and ADHD to be 
available for CSE professionals, and for professionals whose work focuses on young people with learning disabilities to receive training to improve awareness of CSE. The current lack of training can be seen to be directly affecting the identification of, and support made available to, young people with learning disabilities who are at risk of, or experiencing, CSE.

To address and prevent further exploitation requires fundamental change in societal attitudes and approaches to how young people with learning disabilities are treated and supported in the UK. Not least support to reduce social isolation and disempowerment, again an issue that has been identified in studies on abuse of disabled children and young people (Taylor et al, 2014; Miller and Brown, 2014; Taylor et al, 2015; Jones et al, 2016).

The data comprehensively identifies that to support young people with learning disabilities to understand CSE, healthy relationships, consent and risk requires time and attention. All participants in the study concluded that, at present, not enough is being done to support many young people with learning disabilities to develop this understanding and that attention needs to be paid to ensuring that this forms part of every child's education and life experience, developing as they grow into adulthood.

In addition, while noting the benefits that technological developments can bring to the lives of young people with learning disabilities, the research also identifies that young people with learning disabilities are particularly vulnerable to online grooming and CSE. This particular vulnerability creates the need for these young people to receive good advice about internet safety as part of preventative strategies.

Although this was not a prevalence study the research highlights an issue concerning the reported significant number of young people who became known to CSE services, who have moderate or mild learning disabilities and, in particular, autistic spectrum conditions (ASC) and attention deficit hyperactivity disorder (ADHD). These young people were often not known to any services before referral and had not had access to support to meet their needs. In some cases, this lack of support appeared to be directly linked to the high threshold for disability services, lack of alternative provision to meet their needs and a low level of understanding of their impairments and their potential impact on young people's lives. Young people clearly articulated how the lack of recognition that they have a learning disability can be problematic, leading to frustration at school and exhibiting behaviour described by others as 'challenging'. For some, problems at school led them to cease engaging in education or being excluded, which further increased their vulnerability to CSE. Evidence gathered also suggests that professionals may have a propensity to focus on 'challenging behaviour' and miss indicators of a potential learning disability and/or CSE. Many also identified that a formal diagnosis is particularly crucial to meeting young people's 
needs because, in many instances, it is the only route to accessing additional specialist support. Although this warrants further investigation, this does indicate a failing of services to meet the needs of a potentially vulnerable group of young people. These young people will continue to remain invisible given the reported general lack of collation of data relating to young people with learning disabilities. The need to more fully understand the prevalence and specific nature of the sexual exploitation of this group of young people is vital if support and services are to be developed to better prevent it and have adequate services in place to support those who are affected or at risk.

Where young people with learning disabilities are mentioned in national policy and guidance concerning CSE, the particularly limited direction for services to meet the needs of this group is an identified challenge to improving both preventative and responsive measures. This research supports previous studies which have called for statutory and practice guidance concerning CSE to be fully implemented (See for example, Berelowitz et al, 2015; Jago et al, 2011) and in addition, that a spotlight is placed within this on young people with learning disabilities. The necessity for improvements in multi-agency working, including informationsharing generally has previously been noted and recommended by a number of reports concerning CSE (Jay, 2014; Smeaton, 2013; Berelowitz et al, 2015).This research again highlights the crucial importance of effective multi-agency working to meet the needs of young people with learning disabilities who experience, or are at risk of, CSE.

\section{Conclusion:}

This exploratory study aimed to shed light on the previously unexplored issue of the sexual exploitation of young people with learning disabilities. The consistently reported challenges facing professionals working to prevent CSE, and/or support those at risk or who have experienced CSE were significant. This study also gathered the views of those young people who were receiving some support. Those who have not been identified and supported by services remain unheard so little is known about the effect of sexual exploitation on the lives of these young people. Clearly, substantial challenges lie ahead if the UK are to address the sexual exploitation of young people with learning disabilities. Whilst there is much still to learn, this study offers some indication of how to move forward and identifies issues that need to be addressed. These include education, training and awareness raising amongst young people, their families and professionals, tackling social isolation, disempowerment and invisibility of young people with learning disabilities and the need for full implementation of government guidance with more spotlight on this group of young people. It is hoped that this study will be a catalyst for the development of an improved evidence base on the sexual exploitation of disabled young people. 


\section{Acknowledgements:}

We are would like to acknowledge the support provided by our voluntary sector partners, Phil Raws at The Children's Society, Keith Smith from The British Institute of Learning Disabilities and Cassie Harrison from Barnardos. We wish to thank the young people and professionals who contributed to this research and acknowledge the funding and support provided by Comic Relief. 


\section{References:}

Beckett (2011) Not a world away: The sexual exploitation of children and young people in Northern Ireland. Barnardo's NI, Northern Ireland.

http://www.barnardos.org.uk/13932_not_a_world_away_full_report.pdf. Accessed 30 April 2016.

Bedford, A (2015) Serious case review into child sexual exploitation in Oxfordshire: from the experiences of Children $A, B, C, D, E$, and $F$. Oxfordshire Safeguarding Children Board. www.oscb.org.uk/wp-content/uploads/SCR-into-CSE-in-Oxfordshire-FINAL.pdf Accessed 30 April 2016.

Berelowitz, S; Clifton, J; Firmin, C; Gulyurtlu, S; Edwards, G (2013) "If only someone had listened": The Office of the Children's Commissioner's inquiry into child sexual exploitation in gangs and groups.

http://www.childrenscommissioner.gov.uk/sites/default/files/publications/lf_only_someone_h ad_listened.pdf. Accessed 30 April 2016

Berelowitz, S; Ritchie, G; Edwards, G; Gulyurtlu, S; Clifton, J (2015) "If it's not better, it's not the end": Inquiry into child sexual exploitation in gangs and groups: One year on. http://www.childrenscommissioner.gov.uk/sites/default/files/publications/lf\%20its\%20not\%20 better\%20its\%20not\%20the\%20end_web\%20copy.pdf. Accessed 30 April 2016

Brodie, I; Pearce, J (2012) Exploring the scale and nature of child sexual exploitation in Scotland. http://www.scotland.gov.uk/Resource/0040/00404853.pdf, accessed 30 April 2016.

Brown, S., Brady. G., and Franklin A (2016) Child Sexual Abuse and Exploitation: Understanding risk and vulnerability. The Home Office and Early Intervention Foundation. London. http://www.eif.org.uk/publication/csa-risk-and-vulnerability/. Accessed 5 November 2016.

Child Exploitation and Online Protection Centre (2011) Out of mind, out of sight: Breaking down the barriers to understanding child sexual exploitation. Child Exploitation and Online Protection Centre, London.

http://www.ceop.police.uk/Documents/ceopdocs/ceop_thematic_assessment_executive_su mmary.pdf. Accessed 30 April 2016

Coffey, A (2014) Real Voices: Child Sexual Exploitation in Greater Manchester. http://anncoffeymp.com/wp-content/uploads/2014/10/Real-Voices-Final.pdf, Accessed 30 April 2016.

Davies, M (2013) Sexual abuse and exploitation: The experience of people with learning disabilities. Mencap, Brook and FPA. London.

Department for Children, Schools and Families (2009) Safeguarding children and young people from sexual exploitation. DCSF, London.

https://www.gov.uk/government/publications/safeguarding-children-and-young-people-fromsexual-exploitation-supplementary-guidance. Accessed 30 April 2016.

Department of Health (2001) Valuing People: A new strategy for learning disability for the $21^{\text {st }}$ century. Department of Health. London. 
Franklin, A. \& Doyle, L. (2013). Still at Risk: A review of support for trafficked children. Refugee Council and The Children's Society. London. http://www.refugeecouncil.org.uk/assets/0002/9408/Still_at_Risk-Report-final.pdf. Accessed 30 April 2016.

Fox, C (2016) 'It's not on the radar'- The hidden diversity of children and young people at risk of sexual exploitation in England. Barnardos. Barkingside.

http://www.barnardos.org.uk/it_s_not_on_the_radar_report.pdf. Accessed 30 April 2016

Health and Social Care in Northern Ireland (2014) Interim regional guidance: Management of child sexual exploitation referrals. Health and Social Care in Northern Ireland.

http://www.belb.org.uk/Downloads/cpsss_management_of_child_sexual_exploitation_referra Is.pdf. Accessed 30 April 2016.

Hershkowitz , I., Lamb, M.E. and Horowitz, D. (2007) Victimization of disabled children. American Journal of Orthopsychiatry, 77, (4), pp629-635. DOI: 10.1037/0002-9432.77.4.629

Jago, S. with Arocha,L. ,Brodie,I., Melrose,M., Pearce, J. and Warrington.C. (2011) What's going onto Safeguard Children and Young People from Sexual Exploitation? How local partnerships respond to child sexual exploitation. University of Bedfordshire. Luton. http://www.beds.ac.uk/_data/assets/pdf_file/0004/121873/wgoreport2011-121011.pdf. Accessed 30 April 2016.

Jay, A (2014) Independent inquiry into child sexual exploitation in Rotherham 1997-2013 http://www.rotherham.gov.uk/downloads/file/1407/independent_inquiry_cse_in_rotherham, accessed 30 April 2016.

Jones, J., Bellis, M. A., Wood, S., Hughes, K., McCoy, E., Eckley, L., Bates, G., Mikton, C., Shakespeare, T., \& Officer, A. (2012). Prevalence and risk of violence against children with disabilities: A systematic review and meta-analysis of observational studies. The Lancet, 380, September 8. DOI : 10.1016/S0140-6736(12)60692-8

Jones, C., Stalker, K., Franklin, A., Fry, D., Cameron, A. and Taylor (2016) Enablers of helpseeking and protection from abuse for deaf and disabled children: a qualitative study. Child and Family Social Work. Accepted for publication. DOI: 10.1111/cfs.12293

Marshall, K (2014) Child sexual exploitation in Northern Ireland: Report of the independent inquiry. The Regulation and Quality Improvement Authority, Northern Ireland. www.cjini.org/CJNI/files/f0/f094f421-6ae0-4ebd-9cd7-aec04a2cbafa.pdf . Accessed 30 April 2016.

Miller, D and Brown, J (2014) "We have a right to be safe": Protecting disabled children from abuse. NSPCC, London.

https://www.nspcc.org.uk/globalassets/documents/research-reports/right-safe-disabledchildren-abuse-summary.pdf. Accessed 30 April 2016.

National Working Group on Child Protection and Disability (2003) "It doesn't happen to disabled children": Child Protection and Disabled Children. NSPCC, London.

National Working Group on Safeguarding Disabled Children (2016) Safeguarding Disabled Children: How Local Safeguarding Children Boards are delivering against Ofsted requirements to protect disabled children: Findings from a national survey. NWGSDC, 
London. https://www.nspcc.org.uk/services-and-resources/research-and-

resources/2016/safeguarding-disabled-children-england/. Accessed 5 November 2016.

Ofsted (2012) Protecting Disabled Children. Thematic Inspection. Ofsted Manchester.

Ritchie, J; Spencer, L (1994) Qualitative data analysis for applied policy research. In A Bryman and R Burgess (eds). Analysing qualitative data. Routledge, London, pp 173-194.

Rochdale Borough Safeguarding Children Board (2012) Review of multi-agency responses to the sexual exploitation of children. Rochdale: Rochdale Borough Safeguarding Children Board. https://www.rbscb.org/news/news-archive.aspx?ID=23. Accessed 30 April 2016.

Safeguarding Board for Northern Ireland (2013) Strategic plan 2013-2016. SBNI, Northern Ireland.

http://www.safeguardingni.org/sites/default/files/sites/default/files/imce/15.04.13\%20SBNI\%2 0Strategic\%20Plan\%20Version\%201.0.pdf. Accessed 30 April 2016.

Scottish Government (2014) National Guidance for Child Protection in Scotland. The Scottish Government,Edinburgh. http://www.gov.scot/Resource/0045/00450733.pdf. Accessed 30 April 2016.

Scottish Government (2014) Scotland's national action plan to tackle child sexual exploitation. http://www.gov.scot/resource/0046/00463120.pdf. Accessed 30 April 2016.

Shakespeare, T., Gillespie-Sells, K., and Davies, D. (1996) The sexual politics of disability: untold desires. Cassell, New York.

Smeaton, E (2009) Off the radar: Children and young people living on the streets in the UK. Railway Children, Sandbach.

http://www.railwaychildren.org.uk/media/11701/off-the-radar-summary.pdf. Accessed 30 April 2016.

Smeaton, E (2013) Running from hate to what you think is love: The relationship between running away and child sexual exploitation. Barnardo's, London.

http://www.barnardos.org.uk/15505_cse_running_from_hate_2l_web.pdf. Accessed 30 April 2016.

Stalker, K., Lister, P., Lerpiniere, J. \& McArthur, K. (2010) Child Protection and the Needs and Rights of Disabled Children and Young People: A Scoping Study. University of Strathclyde, Glasgow.

Taylor, J; Cameron, A; Jones, C; Franklin, A; Stalker, K and Fry D (2015) Deaf and disabled children talking about child protection. University of Edinburgh NSPCC Child Protection Research Centre. Edinburgh. http://www.nspcc.org.uk/services-and-resources/research-andresources/deaf-disabled-children-talking-about-child-protection . Accessed 30 April 2016.

Taylor, J; Stalker, K; Fry, D; Stewart, ABR (2014) Disabled children and child protection in Scotland: An investigation into the relationship between professional practice, child protection and disability. Scottish Government Social Research, Edinburgh.

www.gov.scot/Resource/0044/00447850.pdf. Accessed 30 April 2016

The Scottish Parliament (2014) Public Petitions Committee 1st Report, 2014 (Session 4): Report on tackling child sexual exploitation in Scotland. 
http://www.parliament.scot/parliamentarybusiness/CurrentCommittees/71818.aspx. Accessed 30 April 2016.

Welsh Assembly Government (2011) Safeguarding Children and Young People from Sexual Exploitation: Supplementary guidance to Safeguarding Children: Working Together Under The Children Act 2004. Welsh Assembly Government, Cardiff. http://gov.wales/docs/dhss/publications/policy/110107guidanceen.pdf. Accessed 30 April 2016.

WithScotland (2014) Child Protection and Disability Toolkit. WithScotland and The Scottish Government. Edinburgh. WithScotland. http://withscotland.org/resources/child-protectionand-disability-toolkit, accessed 30 April 2016. 
Recognising and responding to young people with learning disabilities who experience, or are at risk of, child sexual exploitation in the UK.

\section{Highlights:}

- Young people with learning disabilities are at particular risk of being sexually exploited.

- This group face additional barriers to protection from child sexual exploitation than their non-disabled peers.

- They do not receive enough information or education on sex, relationships and how to keep safe.

- Professionals often fail to recognise the sexual exploitation of young people with learning disabilities.

- More prevention work and support needs to be available to better protect young people with learning disabilities. 